\title{
Comparative Study of Adsorption Phenomena of Direct Dye Black E by Palm Nut Shell Carbon and Treated Flyash Residue With Respect to Activated Charcoal Carbon
}

\author{
C. Palanivel ${ }^{1, \star}$, L. D. Prabhakar ${ }^{2}$, M. Emayavaramban $^{1}$ \\ ${ }^{1} P G$ and Research Dept. of Chemistry, Government Arts College, C. Mutlur, \\ Chidambaram - 608102, Tamilnadu, India \\ ${ }^{2}$ Department of Chemistry, Annamalai University, Annamalai Nagar - 608 002, Tamil Nadu, India \\ *E-mail address: cpalaniivel@gmail.com
}

\begin{abstract}
Many researchers ${ }^{1-3}$ aimed to study the removal of colouring matter from textile dyeing industrial effluent using the carbon derived from natural sources. Because adsorption of the dyes on carbon is easily, cost effective when comparing to the other techniques. Hence we aimed at the preparation and characterization of the carbon from the natural sources like palm nut shell and flyash. These carbons have been used for adsorption of direct dye Black E. The effect of $\mathrm{pH}$, carbon dose and equilibration period were examined along within the Langmuir and Freundlich isotherm studies. The application of these carbons was investigated on adsorption and colour removal from effluent and synthetic samples, which consists of commercial direct dye Black E.
\end{abstract}

Keywords: Adsorption phenomena; palm nut shell carbon; treated flyash residue; direct dye Black E

\section{INTRODUCTION}

Dyeing is one of the fundamental operation in textile industry. The textile wastes are one of the most potential pollutants of our aquatic environment. Dyes are aromatic amines consisting of different types of organic functional groups like phenols ${ }^{4}$ and heavy metals embodied in the basic structure and are confirmed carriers by heavy metals like chromium ${ }^{5}$, copper $^{6}$ and cobalt ${ }^{7}$. Textile dye effluents are complex in chemical nature, highly coloured materials and exhibit toxicity to both aquatic and non-aquatic biota.

Adsorption process is the most powerful technique and used for separating organic and inorganic pollutants from water and waste water and it is embodied in carbon adsorption systems and ion exchangers. Poots et al. ${ }^{8}$ studied the removal of dyes from effluent using natural adsorbents like wood and peat.

Adsorption process was first observed in solution phase by Lowitz ${ }^{9}$. The significance of the carbon surface chemistry in the adsorption process was first raised by Hassler ${ }^{10}$.

Researchers ${ }^{11}$ have investigated the removal of dyes from the effluent water which was released by large tiny printing and dyeing units in the sanganer town- now a part of Jaipur city, using activated charcoal as adsorbent. In this direction we have undertaken an investigation on the effluent pollutions caused by the textile industries situated at Tirpur in South Tamilnadu where direct dyes were used mainly. 
The present paper aims to develop a low cost adsorbent and apply it for removal of the direct dye Black E. Low cost carbon was prepared from palm nut shells. Treated flyash residue (carbon enriched flyash) also selected. The adsorbent capacities of the low cost carbon and Treated Flyash Residue (TFR) were compared with that of a commercial Activated Charcoal Carbon (ACC).

\section{EXPERIMENTAL METHODS}

Four parts of dry palm nut shells were treated with two parts of concentrated $\mathrm{H}_{2} \mathrm{SO}_{4}$ and keeping it in an air oven at $140-170{ }^{\circ} \mathrm{C}$ for 24 hours. The carbonized material was filtered and washed with water to remove the excess acid and direct at $110^{\circ} \mathrm{C}$ and was designated as PNSC.

The flyash was obtained from Neyveli Lignite Corporation of Tamilnadu, India. The raw flyash was treated with cold and hot running water and then with $400 \mathrm{ml}$ of concentrated $\mathrm{H}_{2} \mathrm{SO}_{4}$ and kept it in an air oven at $110-140{ }^{\circ} \mathrm{C}$ for five hours. The settled residue (mostly carbon) material was filtered and washed with water to remove the excess acid and dried at $105-110{ }^{\circ} \mathrm{C}$.

The dried treated flyash carbon was washed to with organic solvents (benzene, ether, acetone) and dried at in an air oven. The dried residue is designated as Treated Flyash Residue (TFR). The ACC, PNSC and TFR materials were grounded well and sieved to an average diameter of $0.5 \mathrm{~mm}$. The activated charcoal carbon (ACC) was obtained from chemical laboratory of qualigens make (Analytical grade).

\section{RESULTS AND DISCUSSION}

\section{1. Charaterization of carbon sample}

The carbon samples (adsorbents) were characterized after following ISI code and the results were tabulated in Table 1 .

\section{1. 1. SEM of Carbon Sample}

The shape and size of the particles of the carbon samples were examined through SEM photographs (Fig. 1-3). The surface of the carbon samples were irregular and not spherical as expected. In the crystallinity is found to be more in activated charcoal carbon (ACC) than that of palmnut shell carbon (PNSC). In the case of treated fly ash residue (TFR) the conglomeration of carbon particles results into bulky mass. This conglomeration reduces the surface area and hence except low adsorption. Another future identifiable is low degree of spherical shape. This is not present in other two samples. ACC is more crystalline but not spherical in shape.

Among the direct dyes Black $\mathrm{E}\left(\lambda_{\max }: 585 \mathrm{~nm}\right)$ was extensively used and discharged into the drain system. The direct dye black $\mathrm{E}$ was obtained from Tirupur dyeing industries in Tamilnadu, India. We concentrate on the adsorption of direct dye Black E from the effluent wastewater using palmnut shell carbon and treated flyash residue as an adsorbents. 
Table 1. Characterization of Carbon Sambles

\begin{tabular}{|c|c|c|c|c|}
\hline S. No. & Parameters & $\mathrm{ACC}$ & PNSC & TFR \\
\hline 1. & Moisture content $(\%)$ & 20.8 & 15.2 & 13.6 \\
\hline 2. & Ash content $(\%)$ & 0.21 & 0.72 & 0.42 \\
\hline 3. & Bulk density (g/cc) & 0.47 & 0.67 & 0.74 \\
\hline 4. & $\mathrm{pH}$ & 7.9 & 6.8 & 7.8 \\
\hline 5 . & Carbon soluble in water $(\%)$ & 0.95 & 0.97 & 0.94 \\
\hline 6. & Carbon soluble in acid (\%) & 1.95 & 1.05 & 1.81 \\
\hline 7. & $\begin{array}{l}\text { Decolourizing power }(\mathrm{mg} / \mathrm{g}) \\
\text { methylene blue }\end{array}$ & 112.5 & 73.5 & 72.0 \\
\hline 8. & $\begin{array}{l}\text { Iron content }\left(\times 10^{-6} \mathrm{gm} / \mathrm{gram} \text { of }\right. \\
\text { carbon })\end{array}$ & 811.0 & 1054.3 & 405.5 \\
\hline 9. & Phenol number (mg/lit) & 227.5 & 333.3 & 370.4 \\
\hline 10. & Ion exchange capacity $(\mathrm{mg} / \mathrm{g})$ & 0.4468 & 0.3277 & 0.3872 \\
\hline 11. & $\begin{array}{l}\text { Surface area }\left(\mathrm{m}^{2} / \mathrm{g}\right) \\
(p \text {-nitrophenol method })\end{array}$ & 474.3 & 459.1 & 467.9 \\
\hline
\end{tabular}

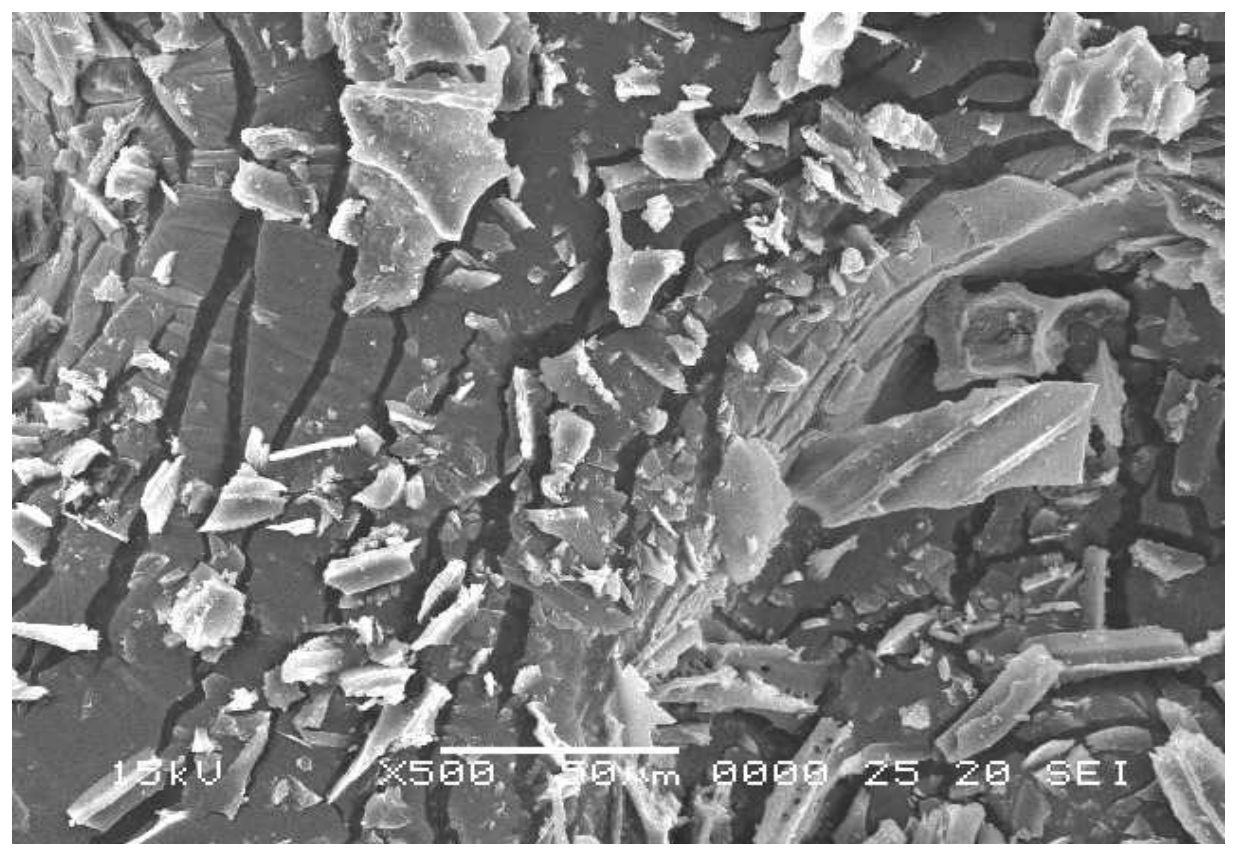

Fig. 1. Activated Charcoal Carbon (ACC) 


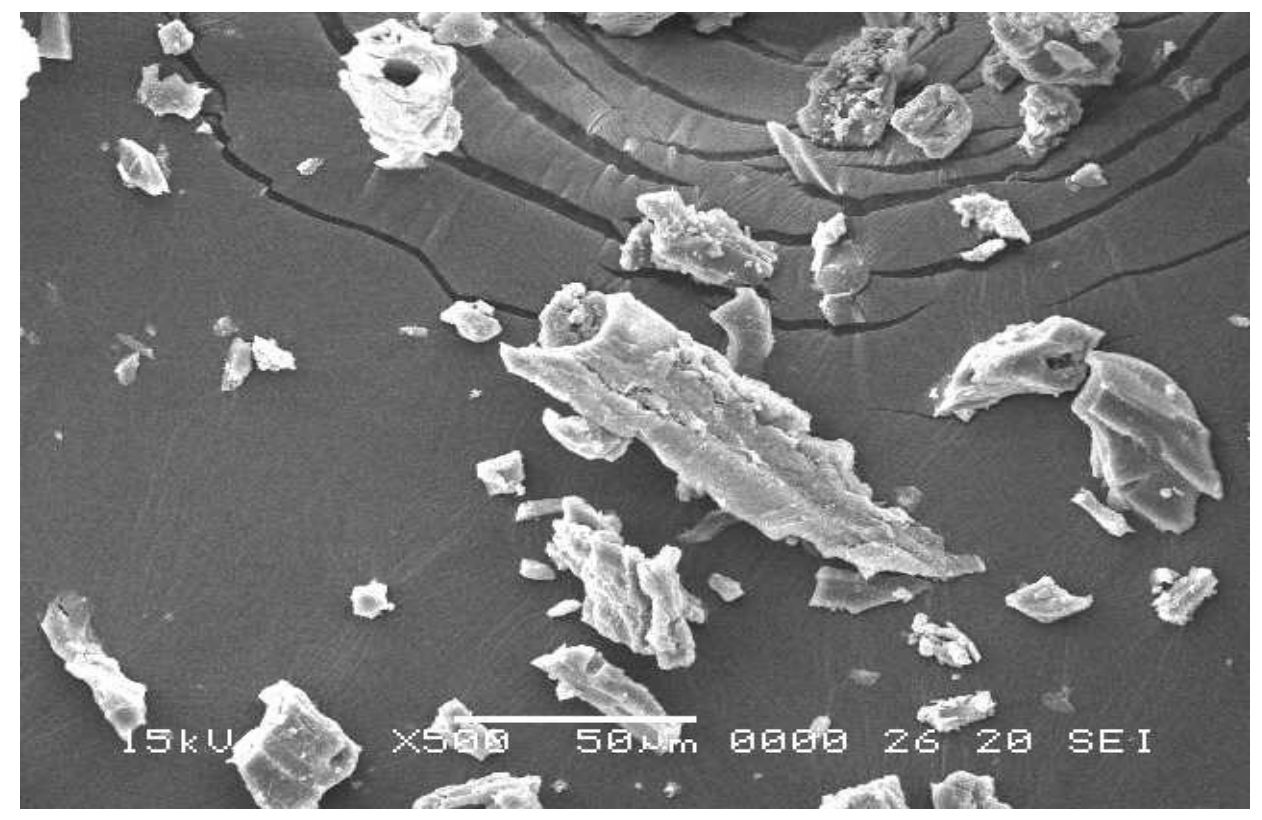

Fig. 2. Palm Nut Shell Carbon (PNSC)

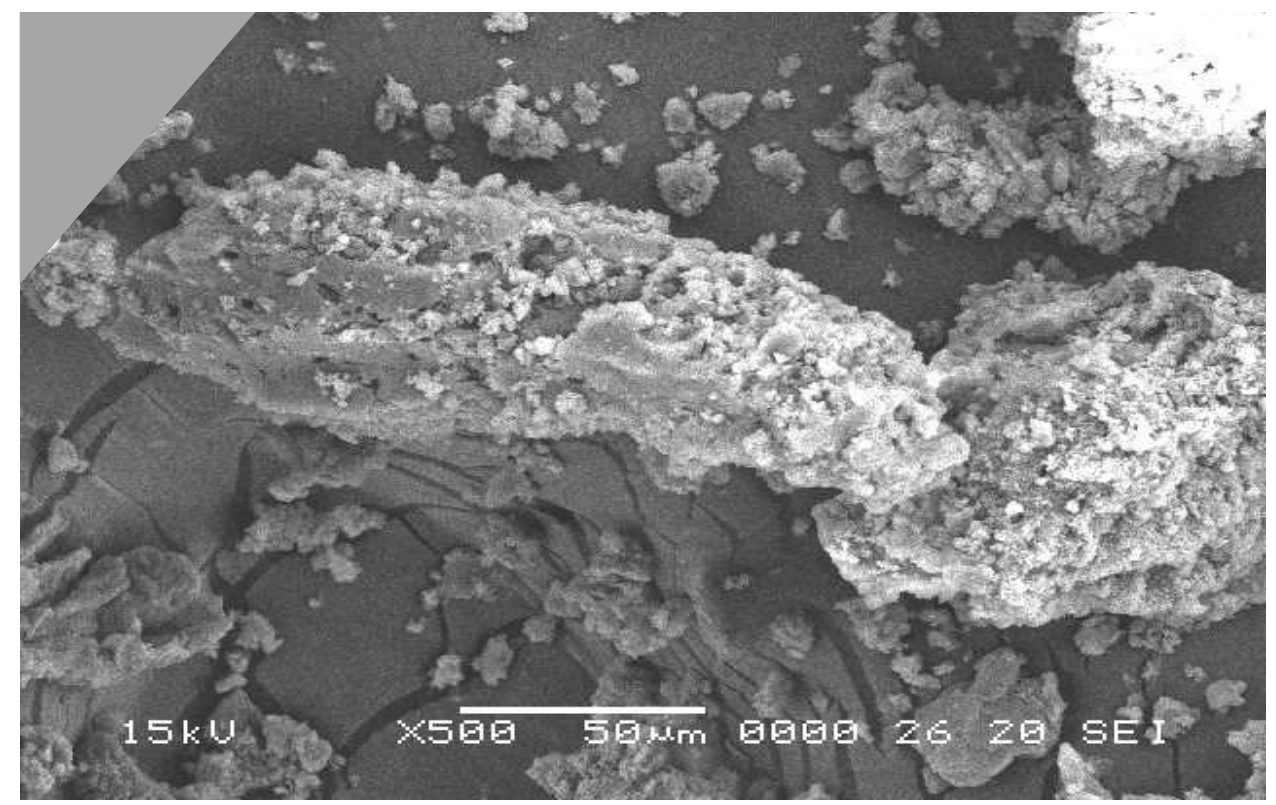

Fig. 3. Treated Flyash Residue (TFR)

\section{2. Batch desorption studies}

5 gram carbon systems were subjected for the maximum adsorption of the black $\mathrm{E}$ dye under optimized condition. The dye adsorbed carbons were filtered off and $0.5 \mathrm{~g}$ of each carbons were treated for desorption studies by mineral acid $\left(\mathrm{HCl}, \mathrm{H}_{2} \mathrm{SO}_{4}\right.$ and $\mathrm{HClO}_{4}$ ), steam and hydrogen peroxide methods. The desorbed carbons were again used for the adsorption of the dye. The process of adsorption and desorption were repeated for 5 times. 


\section{3. Batch isotherm study}

A batch experiment was conducted by taking varying amount of adsorbents ranging from $50 \mathrm{mg}$ to $250 \mathrm{mg}$ in polythene bottle and $100 \mathrm{ml}$ of dye solution which vary in concentration from 10-150 ppm under optimum condition. After equilibration period of one hour the absorbance of the supernatant liquid is determined spectrophotometrically at $585 \mathrm{~nm}$.

\section{4. Batch kinetic study}

$100 \mathrm{ml}$ of dye solution with initial concentration of 10,15, $20 \mathrm{ppm}$ were treated each with $1 \mathrm{~g}$ of carbon and equilibrated for different time intervals of 25, 50, 75 and 100 minutes with constant stirring. The residual dye concentrations after equilibration period were measured spectrophotometerically at $585 \mathrm{~nm}$.

The optimized conditions for maximum adsorption of the dye our the carbons in shown in Table 2.

Table 2. The optimized conditions for maximum adsorption of the dye our the carbons.

\begin{tabular}{|c|l|c|c|c|}
\hline S. No. & \multicolumn{1}{|c|}{ Optimized parameters } & ACC & PNSC & TFR \\
\hline 1. & $\mathrm{pH}$ & 7 & 9 & 7 \\
\hline 2. & Carbon dose (g) & 1.0 & 0.9 & 1.1 \\
\hline 3. & Equilibration period (min.) & 330 & 360 & 360 \\
\hline
\end{tabular}

\section{5. Desorption and regeneration studies}

The desorption of the dye from the adsorbed carbon is attempted by mineral acids $(\mathrm{HCl}$, $\mathrm{H}_{2} \mathrm{SO}_{4}$ and $\mathrm{HClO}_{4}$ ), steam and hydrogen peroxide methods. In acid desorption method, the adsorbed carbon is treated with $0.5 \mathrm{~N} \mathrm{H}_{2} \mathrm{SO}_{4}$ separately for 1 hour and the resulted desorbed dye concentration was identified. In steam method, the adsorbed carbons were subjected to the steam flow $\left(100{ }^{\circ} \mathrm{C}\right)$ for a period of 30 minutes and intermission for 10 minutes.

The collected dye is concentrated and identified. In hydrogenperoxide $(30 \% \mathrm{v} / \mathrm{v})$ method, $0.5 \mathrm{~g}$ of adsorbed carbons are mixed with hydrogen peroxide and stirred for 1 hour.

The resulted desorbed dye content is identified. The reusefullness of the carbons are also tested for five times. The results are presented in Table 3. From the table, the adsorbed dye is in most cases is desorbed with much loss reduction in percentage of desorption is 5 to $15 \%$. It is indicates that the adsorption is mostly physical in nature.

\section{6. Equilibration isotherm studies}

The variation of amount of dye adsorbed with initial equilibrium dye concentration (Fig. 4) indicates a sharp increase in the amount adsorbed up to $340 \mathrm{mg} / \mathrm{lt}, 560 \mathrm{mg} / \mathrm{lit}$ and $360 \mathrm{mg} / \mathrm{lit}$ in the case of ACC, PNSC and TFR carbons without a notch.

This is an indicative of homogenous adsorptions mode ${ }^{13,14}$. A plot of $\mathrm{x} / \mathrm{m}$ Vs equilibration dye concentration results in a $\mathrm{L}$ shape $^{15}$ (Fig. 4) indicate of Langmuir assumption that the intermolecular forces between sorbate and sorbent. 
Table 3. Reusability data

\begin{tabular}{|c|c|c|c|c|c|c|c|c|c|c|c|c|c|c|c|c|c|c|}
\hline \multirow{3}{*}{$\begin{array}{l}\frac{\theta}{e} \\
\frac{0}{0} \\
\frac{0}{0} \\
\dot{z}\end{array}$} & \multicolumn{6}{|c|}{$0.5 \mathrm{~N} \mathrm{H}_{2} \mathrm{SO}_{4}$ acid method } & \multicolumn{6}{|c|}{ Steam method } & \multicolumn{6}{|c|}{$\begin{array}{c}30 \% \text { v/v hydrogen } \\
\text { peroxide method }\end{array}$} \\
\hline & \multicolumn{2}{|c|}{$\begin{array}{c}\text { ACC } \\
\text { System (a) }\end{array}$} & \multicolumn{2}{|c|}{$\begin{array}{l}\text { PNSC } \\
\text { System } \\
\text { (b) }\end{array}$} & \multicolumn{2}{|c|}{$\begin{array}{c}\text { TFR } \\
\text { System } \\
\text { (c) }\end{array}$} & \multicolumn{2}{|c|}{$\begin{array}{c}\text { ACC } \\
\text { System } \\
\text { (a) }\end{array}$} & \multicolumn{2}{|c|}{$\begin{array}{l}\text { PNSC } \\
\text { System } \\
\text { (b) }\end{array}$} & \multicolumn{2}{|c|}{$\begin{array}{c}\text { TFR } \\
\text { System } \\
\text { (c) }\end{array}$} & \multicolumn{2}{|c|}{$\begin{array}{c}\text { ACC } \\
\text { System } \\
\text { (a) }\end{array}$} & \multicolumn{2}{|c|}{$\begin{array}{c}\text { PNSC } \\
\text { System } \\
\text { (b) }\end{array}$} & \multicolumn{2}{|c|}{$\begin{array}{c}\text { TFR } \\
\text { System } \\
\text { (c) }\end{array}$} \\
\hline & 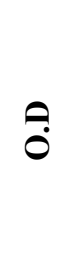 & 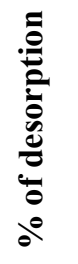 & $\hat{0}$ & 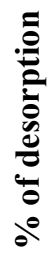 & 0 & 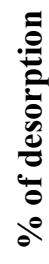 & $\frac{1}{0}$ & 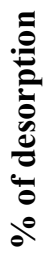 & $\hat{c}$ & eे & & 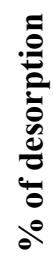 & $\stackrel{0}{0}$ & 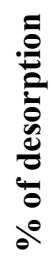 & $\hat{0}$ & 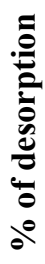 & $\hat{0}$ & 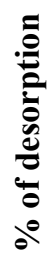 \\
\hline- & $\frac{n}{\infty}$ & ఠి & $\begin{array}{l}\overline{0} \\
\dot{0} \\
0\end{array}$ & $\frac{9}{\pi}$ & $\begin{array}{l}\stackrel{P}{+} \\
\stackrel{0}{0}\end{array}$ & $\stackrel{+}{ָ}$ & $\underset{\infty}{\infty}$ & ดें & $\frac{n}{n}$ & $\bar{\sigma}$ & $\stackrel{\varepsilon}{\varepsilon}$ & $\ddot{n}$ & $\begin{array}{l}n \\
\infty \\
0 \\
0\end{array}$ & $\frac{+}{a}$ & $\stackrel{n}{\frac{n}{0}}$ & $\hat{\infty}$ & $\frac{8}{2}$ & ナே. \\
\hline$N$ & $\frac{0}{2}$ & $\stackrel{m}{\infty}$ & $\begin{array}{l}8 \\
n \\
0\end{array}$ & $\stackrel{0}{\circ}$ & $\frac{n}{0}$ & $\stackrel{0}{0}$ & $\begin{array}{l}n \\
\infty \\
\infty \\
0\end{array}$ & ‡̛ & $\frac{7}{2}$ & $\begin{array}{l}\infty \\
\infty \\
\infty\end{array}$ & o & $\begin{array}{l}n \\
\infty \\
\infty\end{array}$ & $\begin{array}{l}n \\
\infty \\
0\end{array}$ & $\vec{\infty}$ & $\stackrel{\overbrace{}}{0}$ & $\ddot{\infty}$ & $\frac{i}{0}$ & $\underset{\infty}{0}$ \\
\hline$m$ & $\frac{\mathfrak{T}}{\mathfrak{O}}$ & $\overbrace{\infty}^{\infty}$ & $\frac{n}{n}$ & $\begin{array}{l}\infty \\
\infty \\
\infty\end{array}$ & 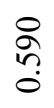 & i̊ & $\begin{array}{l}8 \\
\stackrel{0}{\infty} \\
0 \\
0\end{array}$ & $\stackrel{0}{\infty}$ & $\frac{n}{?}$ & $\stackrel{\Re}{\infty}$ & $\stackrel{2}{\alpha}$ & $\begin{array}{c}N \\
\infty \\
\infty\end{array}$ & $\frac{n}{\mathfrak{r}}$ & $\begin{array}{l}\infty \\
\infty\end{array}$ & $\frac{i}{2}$ & $\stackrel{\infty}{\infty}$ & $\frac{2}{2}$ & $\begin{array}{l}0 \\
i \\
\infty\end{array}$ \\
\hline$\nabla$ & $\frac{\text { I }}{\mathfrak{0}}$ & $\frac{9}{\infty}$ & กิ & $\tilde{\sigma}$ & $\stackrel{n}{n}$ & $\frac{6}{6}$ & $\begin{array}{l}\stackrel{\infty}{0} \\
0\end{array}$ & $\underset{\infty}{+}$ & $\begin{array}{l}\text { @̊ } \\
0\end{array}$ & $\infty$ & $\frac{5}{2}$ & $\stackrel{y}{n}$ & $\frac{0}{0}$ & $\stackrel{8}{\infty}$ & @̊ & ñ & $\frac{n}{2}$ & $\stackrel{\infty}{2}$ \\
\hline in & $\stackrel{\hat{N}}{\hat{0}}$ & $\stackrel{n}{\infty}$ & \begin{tabular}{l}
$\infty$ \\
0 \\
\hdashline \\
0
\end{tabular} & $\stackrel{\infty}{8}$ & ñ & $\hat{a}$ & $\stackrel{\text { શે}}{0}$ & $\grave{\infty}$ & $\begin{array}{l}n \\
\infty \\
0 \\
0 \\
0\end{array}$ & $\frac{\sigma}{\infty}$ & $\frac{1}{n}$ & $\underset{\infty}{\dot{\infty}}$ & $\frac{2}{0}$ & $\stackrel{n}{\infty}$ & $\begin{array}{l}\infty \\
n \\
0 \\
0 \\
0\end{array}$ & $\stackrel{\grave{\infty}}{\infty}$ & $\begin{array}{l}\bar{\sigma} \\
\dot{0} \\
0\end{array}$ & $\underset{\infty}{\infty}$ \\
\hline
\end{tabular}

(a) $\%$ of Adsorption out of $95 \%$

(b) $\%$ of Adsorption out of $88 \%$

(c) $\%$ of Adsorption out of $93 \%$ 

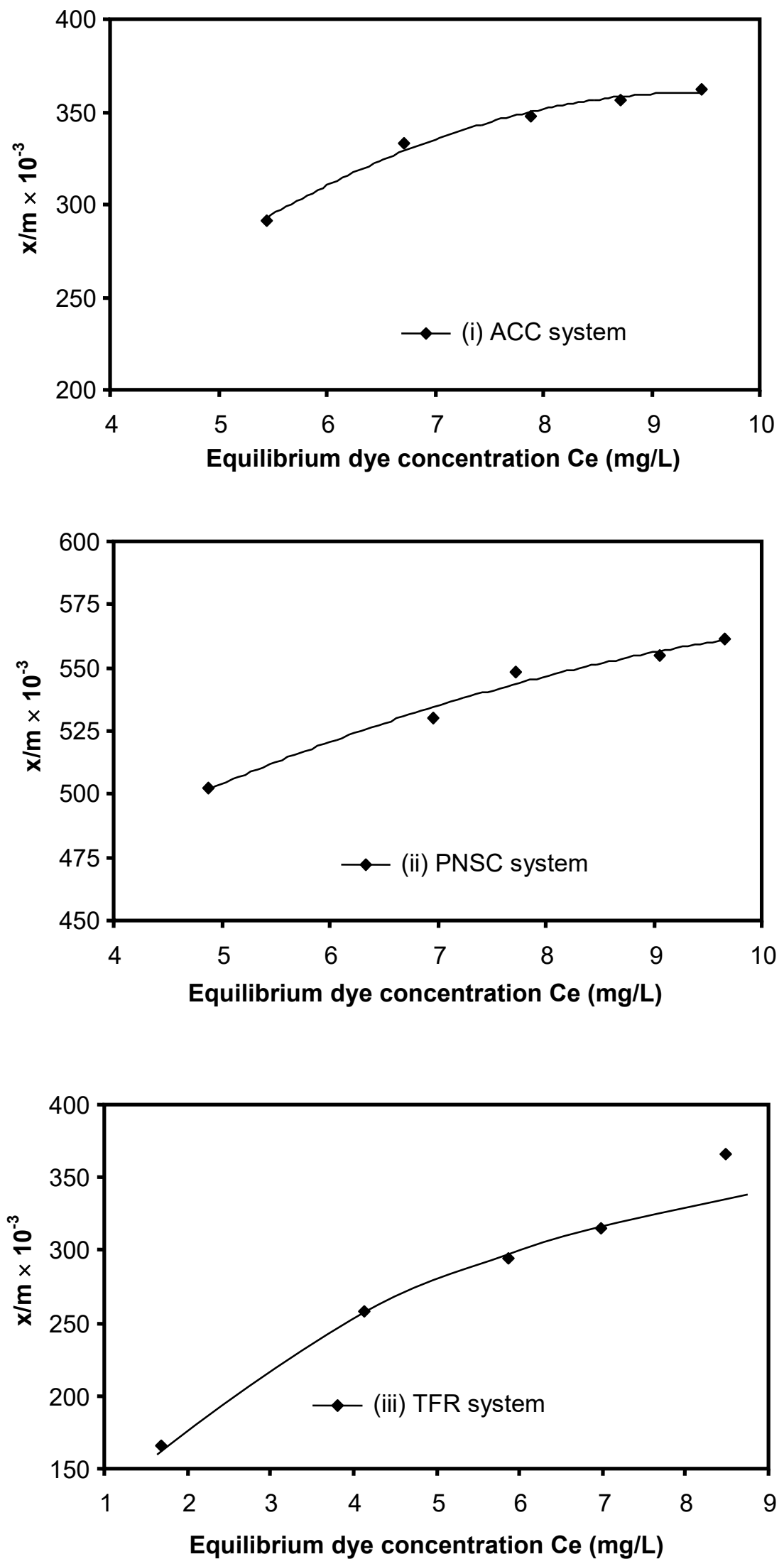

Fig. 4. Equilibrium sorption curves of Black E. 


\section{6. 1. Langmuir adsorption isotherm}

The langmuir plot of $\mathrm{Ce} / \mathrm{x} / \mathrm{m}$ Vs equilibrium dye concentration results in a linear relation was obtained and presented in Fig. 5. From the plot, the essential characteristics of sorption intensity "a" (mg/L) and sorption capacity "b" (mg/g) and linearized Langmuir equations are present in Table 4.

Table 4. Essential characteristics of Langmuir plot.

\begin{tabular}{|c|c|c|c|l|}
\hline S. No. & $\begin{array}{c}\text { Carbon } \\
\text { system }\end{array}$ & $\begin{array}{c}\text { Sorption } \\
\text { intensity 'a' } \\
\mathbf{m g} / \mathbf{L}\end{array}$ & $\begin{array}{c}\text { Sorption } \\
\text { capacity 'b' } \\
\mathbf{m g} / \mathbf{g}\end{array}$ & $\frac{\mathbf{C e}}{\mathrm{x} / \mathrm{m}}=\frac{1}{\mathbf{a b}}+\frac{1}{\mathbf{b}} \mathrm{Ce}$ \\
\hline 1. & ACC & 0.234 & 0.532 & $\frac{\mathrm{Ce}}{\mathrm{x} / \mathrm{m}}=8.02+1.88 \mathrm{Ce}$ \\
\hline 2. & PNSC & 0.748 & 0.637 & $\frac{\mathrm{Ce}}{\mathrm{x} / \mathrm{m}}=2.10+1.57 \mathrm{Ce}$ \\
\hline 2. & TFR & 0.266 & 0.503 & $\frac{\mathrm{Ce}}{\mathrm{x} / \mathrm{m}}=7.46+1.99 \mathrm{Ce}$ \\
\hline
\end{tabular}

\section{6. 2. Freundlich adsorption isotherm}

The experimental data was presented in the form of Fig. 6 was fit into the Freundlich model which is represented by

$$
\log (\mathrm{x} / \mathrm{m})=\log \mathrm{K}+1 / \mathrm{n} \log \mathrm{Ce}
$$

The fit in the data indicates the heterogeneity of the system. The essential characteristics of Freundlich plot are presented in Table 5.

Table 5. Essential characteristics of Freundlich plot.

\begin{tabular}{|c|c|c|c|c|c|c|}
\hline \multirow{2}{*}{ S. No. } & \multicolumn{2}{|c|}{ ACC System } & \multicolumn{2}{c|}{ PNSC System } & \multicolumn{2}{c|}{ TFR System } \\
\cline { 2 - 7 } & $\mathbf{K}$ & $\mathbf{1 / n}$ & $\mathbf{K}$ & $\mathbf{1 / n}$ & $\mathbf{K}$ & $\mathbf{1 / n}$ \\
\hline 1. & 0.148 & 0.406 & 0.378 & 0.180 & 0.129 & 0.473 \\
\hline
\end{tabular}

In the present studies only one line is resulted which testifies the formation of monolayer only on the adsorbent surface ${ }^{16}$. From the adsorption isotherm studies, it is found out that the order of preference for removal of dye is PNSC $>$ ACC $>$ TFR. 

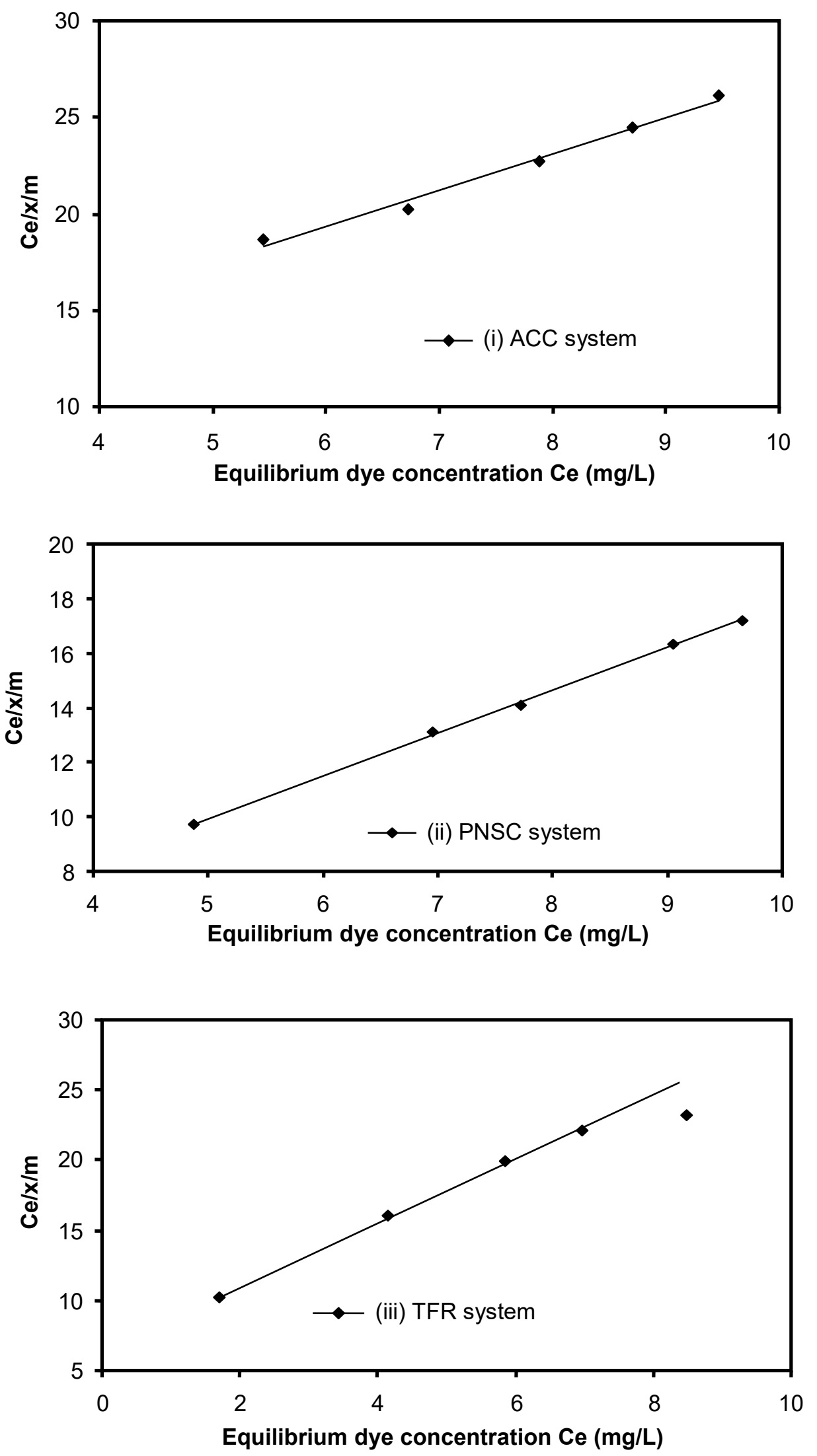

Fig. 5. Langmuir plot of Black E. 

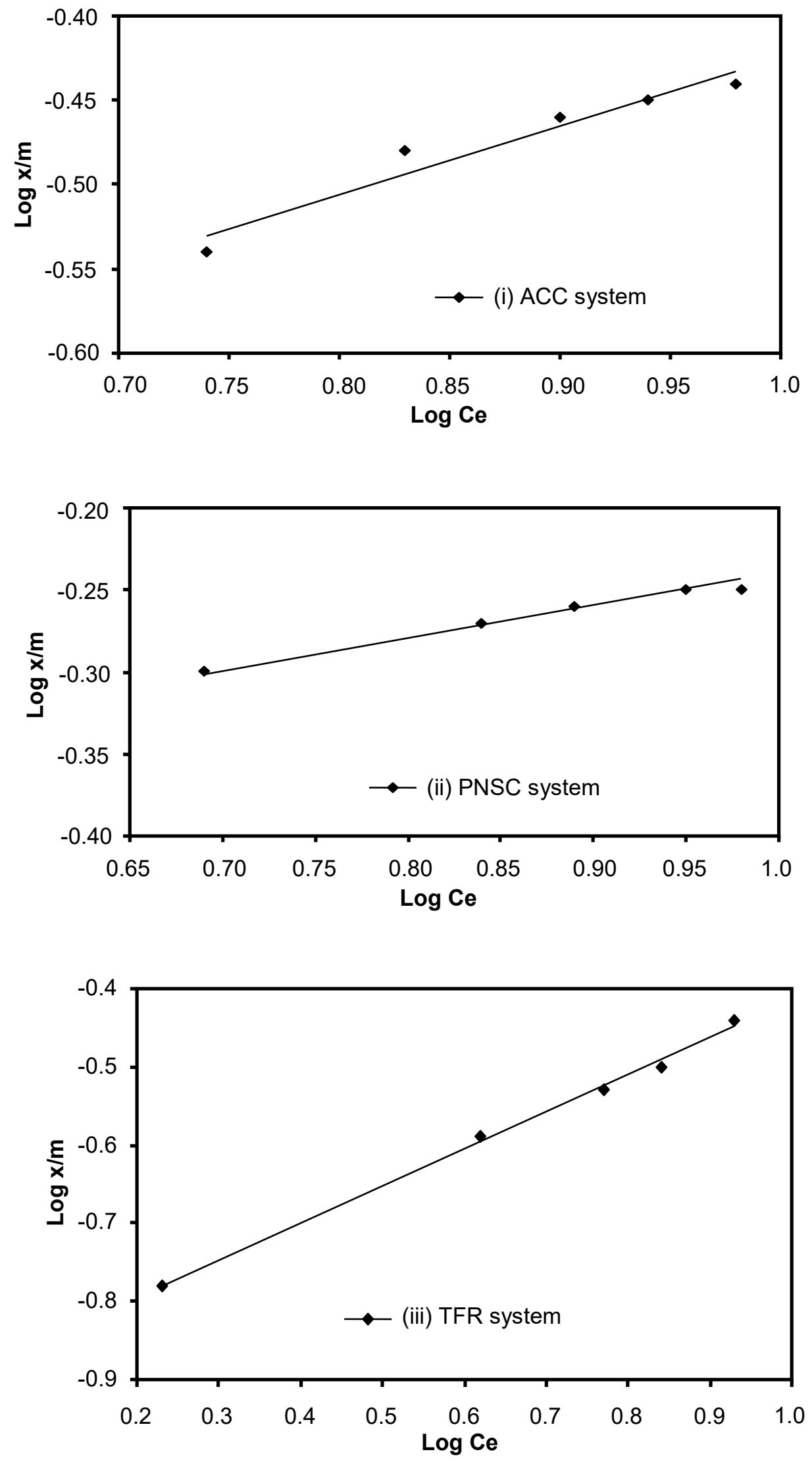

Fig. 6. Freundlich plot of Black E. 


\section{7. Kinetics of adsorption}

The kinetics of adsorption plots are constructed to the concentration of the dye (mg/L) with different time intervals Vs various initial dye concentrations are presented in Fig. 7. All the plots show similar trends with in the limits of study. A significant fact to be noticed is increased percentage of adsorption with increase in initial concentration. The equilibrium concentration also increases with increased initial concentration. Hence, the rate of adsorption also increases with increased initial concentration.

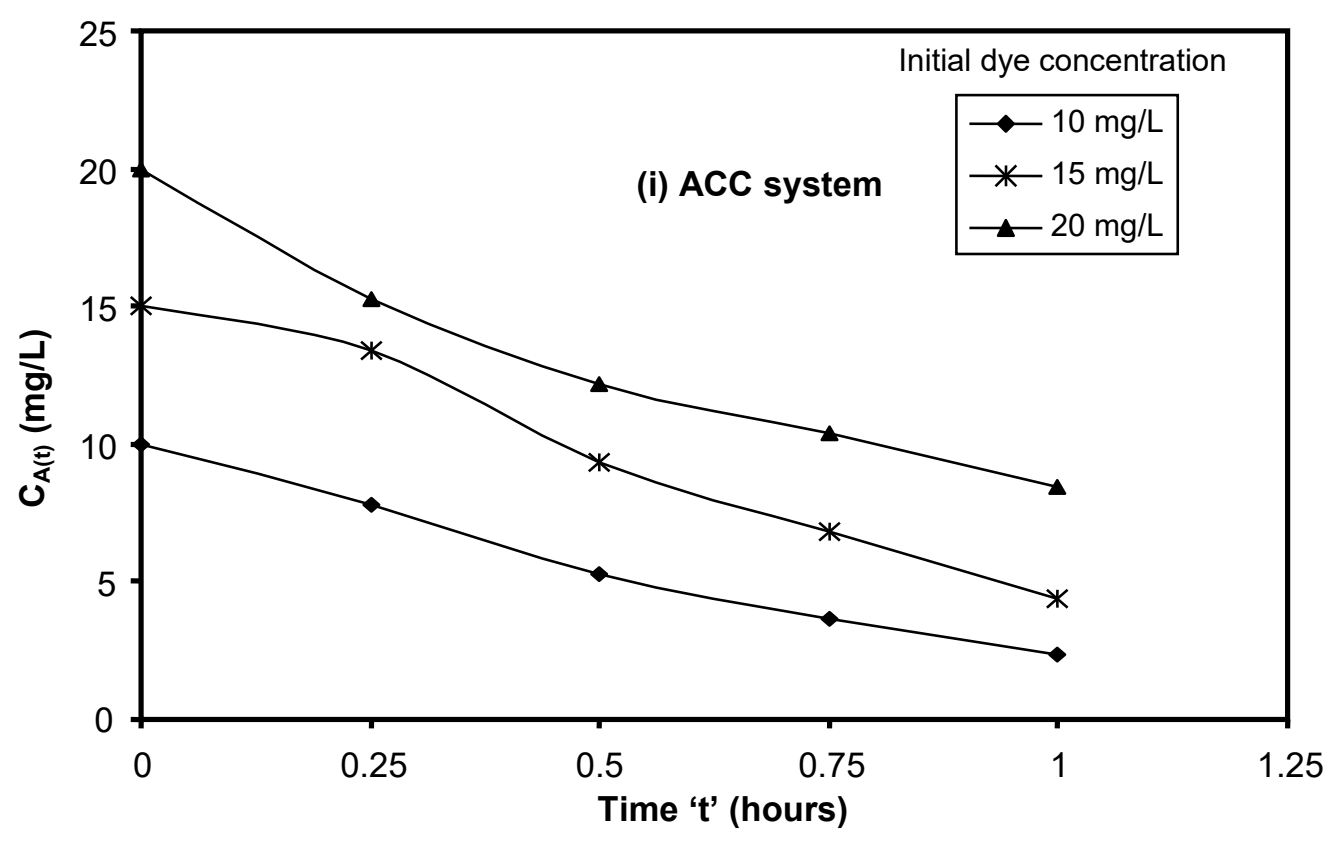

(i) ACC system

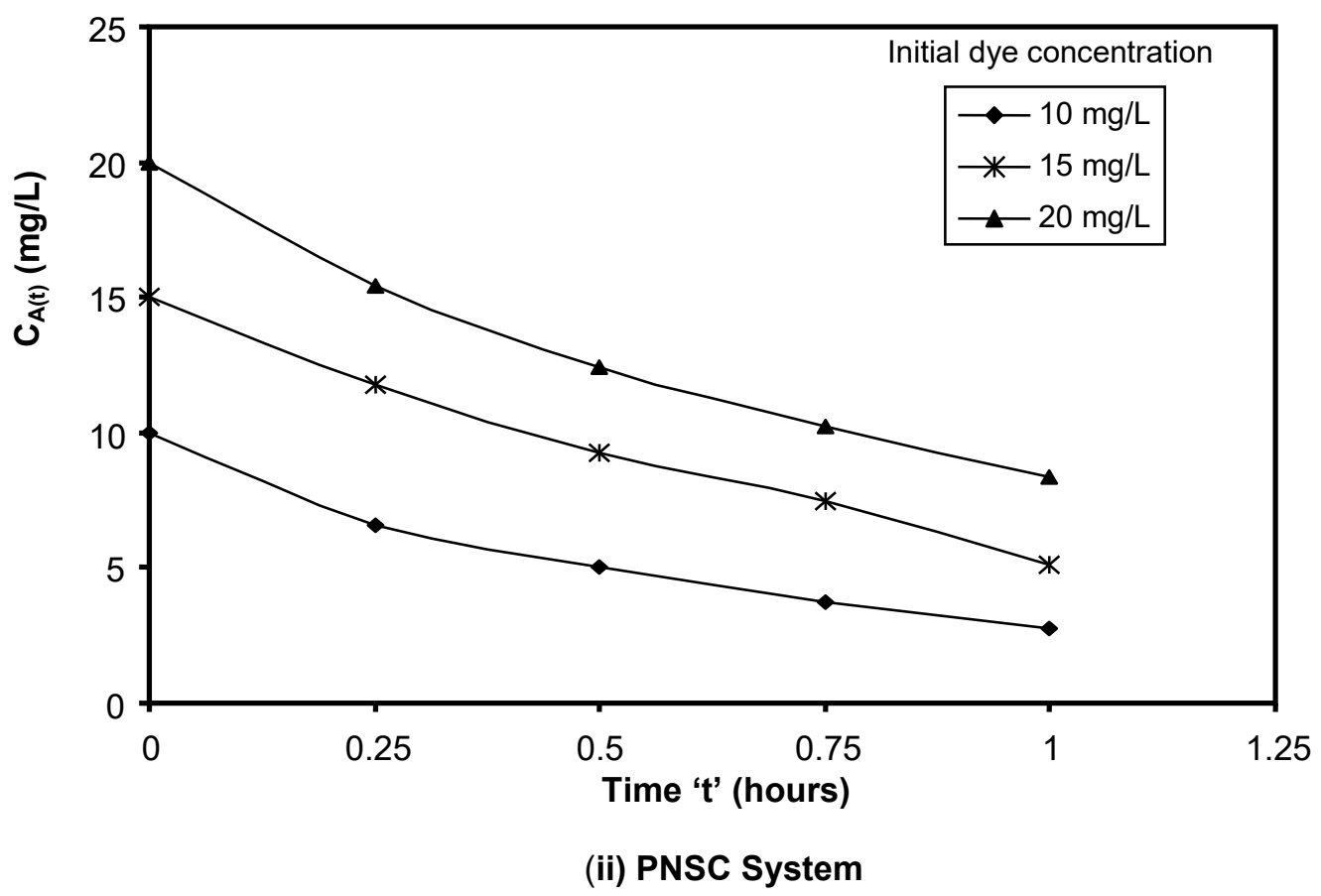




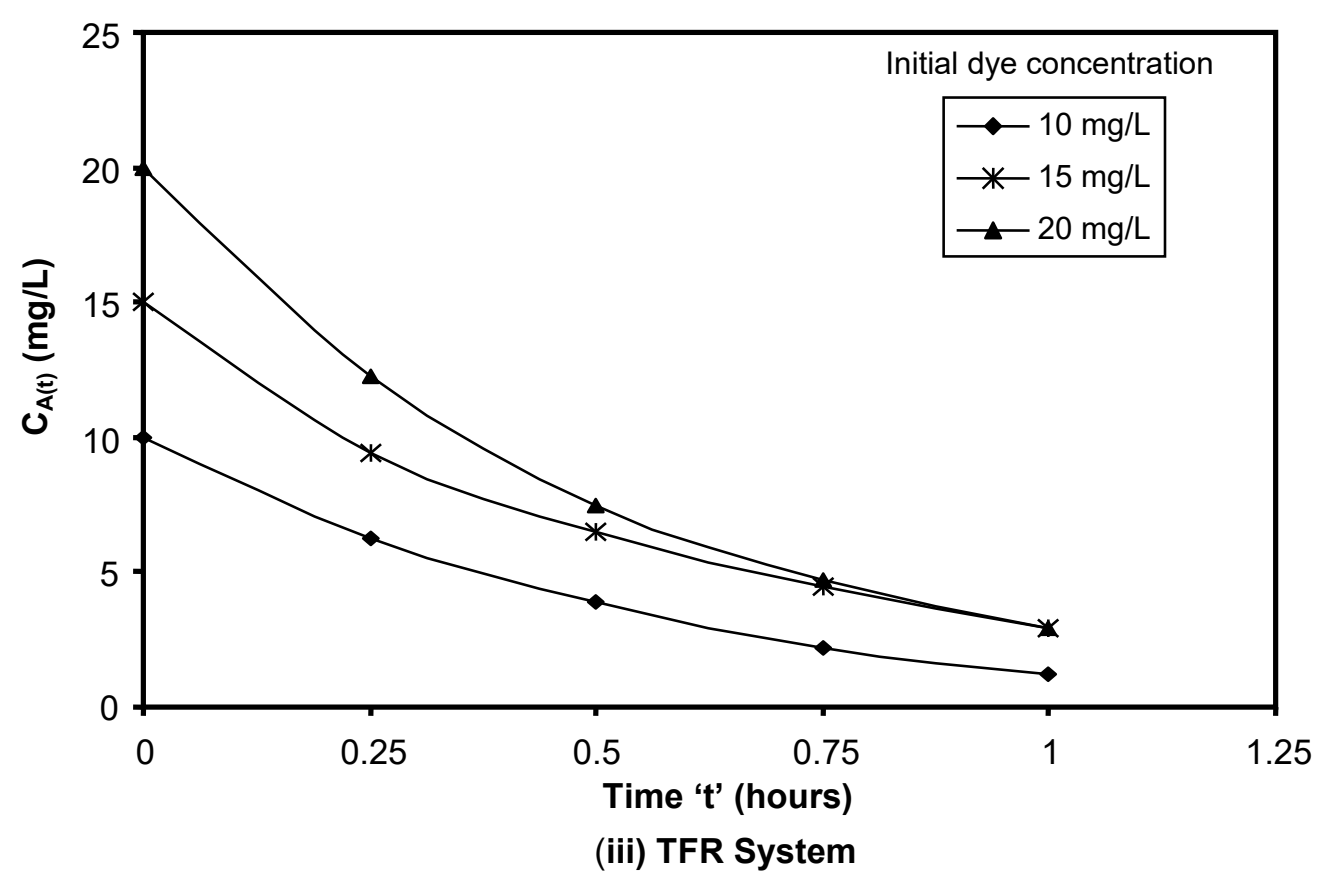

Table 7. Essential characteristics of Freundlich plot.

\section{8. Rate constant studies}

The interpretation of the adsorption data can be best explained with the help of linearized Lagergrem's equation (Fig. 8). The forward and backward rate constant, overall rate of the adsorption and equilibrium constant were calculated and presented in Table 6.

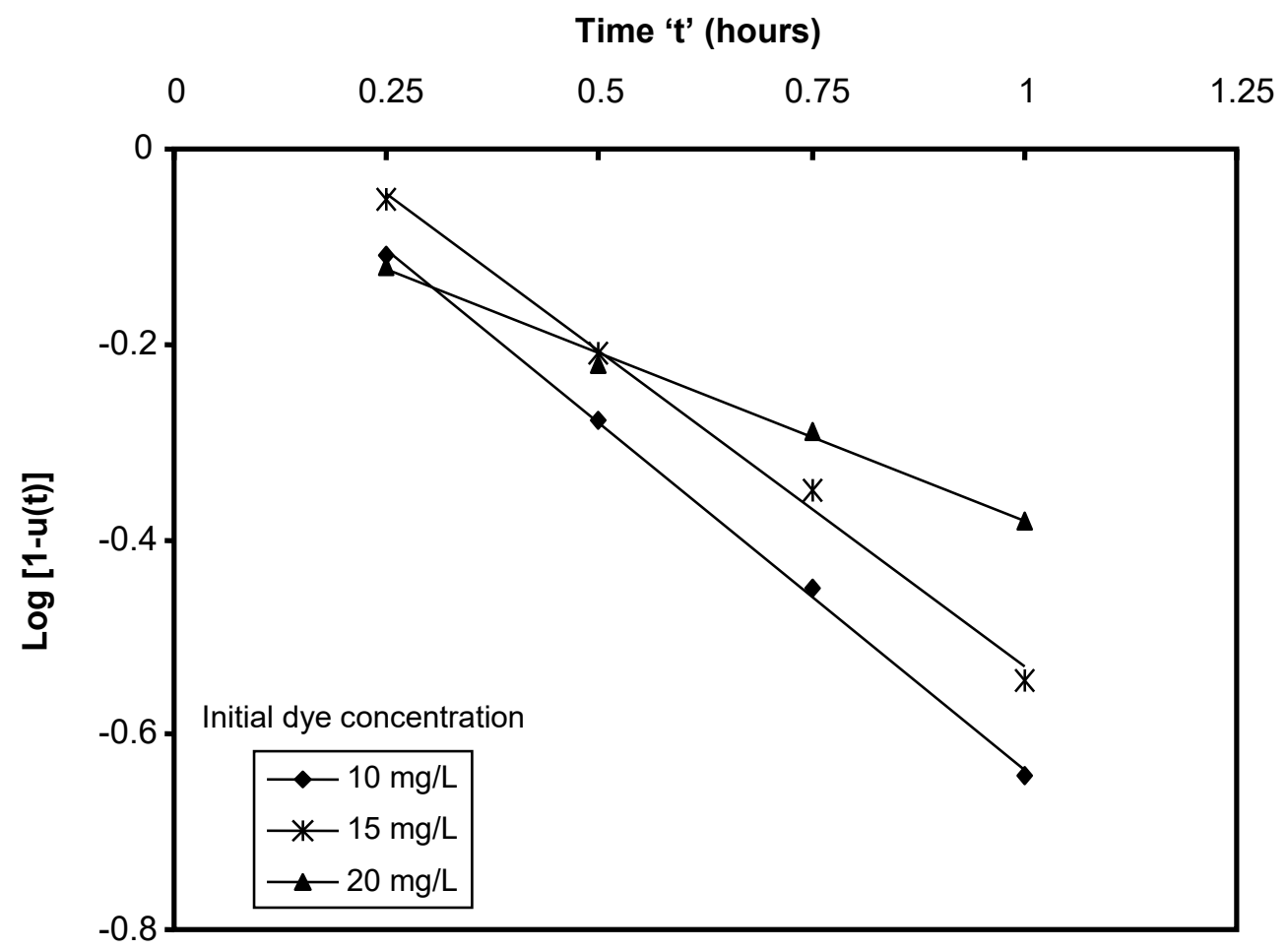

(i) ACC system 

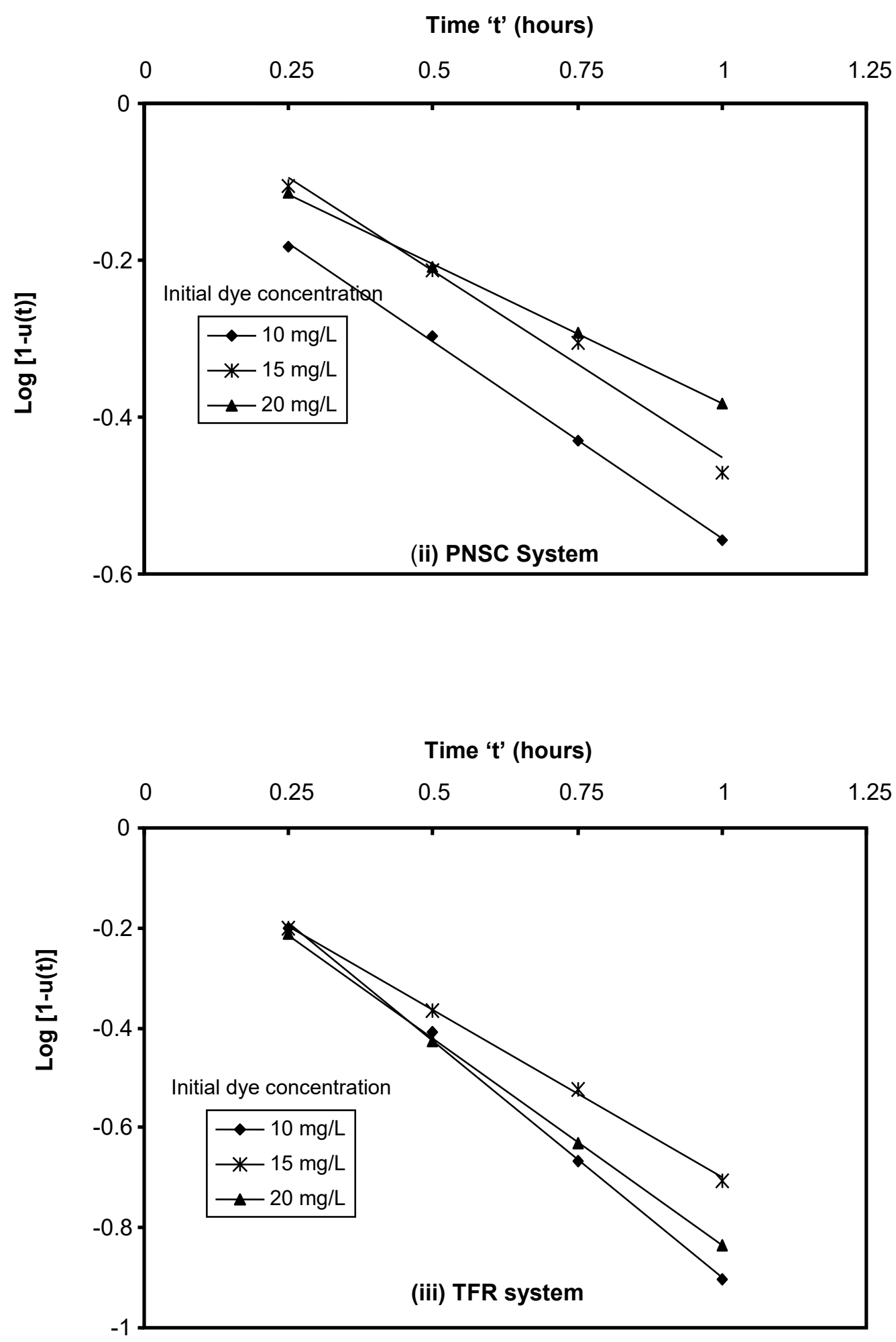

Fig. 8. Rate Constants of Carbon System with Black-E 
Table 6. Rate constants of carbon systems

\begin{tabular}{|c|c|c|c|c|c|c|c|c|c|c|c|c|c|}
\hline \multirow{2}{*}{$\begin{array}{c}\text { S. } \\
\text { No. }\end{array}$} & \multirow{2}{*}{$\begin{array}{c}\text { Initial } \\
\text { dye } \\
\text { conc. } \\
\text { (mg/L) }\end{array}$} & \multicolumn{4}{|c|}{ ACC System } & \multicolumn{4}{|c|}{ PNSC System } & \multicolumn{4}{|c|}{ TFR System } \\
\hline & & $\mathbf{K}$ & $k_{1}$ & $k_{-1}$ & $\mathbf{k}_{\mathrm{C}}$ & $\mathbf{K}$ & $\mathbf{k}_{1}$ & $\mathrm{k}_{\mathbf{1}}$ & $\mathbf{k}_{\mathrm{C}}$ & $\mathbf{K}$ & $\mathbf{k}_{1}$ & $k_{-1}$ & $\mathbf{k}_{\mathbf{C}}$ \\
\hline 1. & 10 & 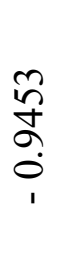 & 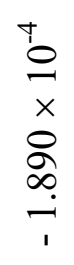 & \begin{tabular}{l}
$\bar{n}$ \\
\multirow{+}{\sigma}{} \\
$\vdots$ \\
1
\end{tabular} & \begin{tabular}{l}
+ \\
\hdashline \\
$\times$ \\
$\times$ \\
8 \\
8 \\
i
\end{tabular} & $\begin{array}{l}\widehat{̃} \\
0 \\
0 \\
0 \\
1\end{array}$ & 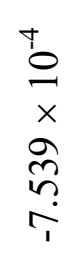 & $\begin{array}{l}0 \\
0 \\
0 \\
0 \\
1\end{array}$ & 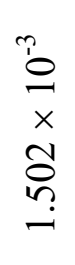 & $\begin{array}{l}\hat{\infty} \\
0 \\
0 \\
0\end{array}$ & $\begin{array}{l}\hat{0} \\
x \\
\hat{\infty} \\
\hat{\infty} \\
1\end{array}$ & 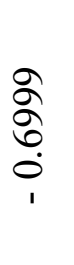 & $\begin{array}{l}\hat{0} \\
\times \\
x \\
n \\
n \\
n \\
\simeq\end{array}$ \\
\hline 2 & 15 & 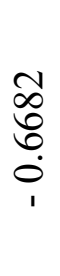 & $\begin{array}{l}+ \\
0 \\
x \\
\dot{b} \\
n \\
\text { n? }\end{array}$ & $\begin{array}{l}\infty \\
\hat{\sigma} \\
0 \\
0 \\
1\end{array}$ & 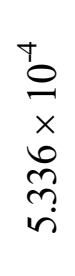 & \begin{tabular}{l}
0 \\
0 \\
\multirow{\sigma}{*}{} \\
0 \\
1
\end{tabular} & $\begin{array}{l}\hat{0} \\
\times \\
\times \\
\sim \\
\tilde{\sigma} \\
\stackrel{7}{1}\end{array}$ & 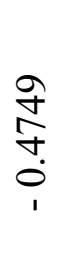 & 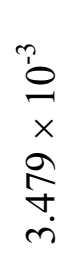 & \begin{tabular}{l}
$\infty$ \\
\multirow{J}{*}{} \\
0 \\
0 \\
1
\end{tabular} & $\begin{array}{l}\hat{0} \\
\times \\
\hat{n} \\
\hat{n} \\
\hat{r}\end{array}$ & $\begin{array}{l}\text { J } \\
\text { đ̛ } \\
0 \\
0 \\
1\end{array}$ & 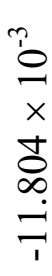 \\
\hline 3 & 20 & $\begin{array}{l}\stackrel{0}{N} \\
\infty \\
0 \\
0 \\
1\end{array}$ & 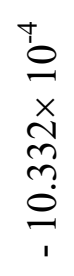 & \begin{tabular}{l}
0 \\
\multirow{2}{1}{} \\
$\infty$ \\
0 \\
1
\end{tabular} & 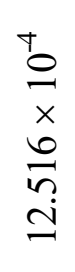 & $\begin{array}{l}\text { J } \\
n \\
? \\
0 \\
1\end{array}$ & 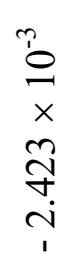 & 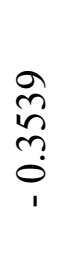 & $\begin{array}{l}3 \\
0 \\
x \\
0 \\
+0 \\
0\end{array}$ & \begin{tabular}{l}
0 \\
\multirow{J}{*}{} \\
0 \\
0 \\
1
\end{tabular} & $\begin{array}{l}\hat{0} \\
x \\
x \\
n \\
\tilde{J} \\
r \\
r\end{array}$ & $\begin{array}{l}\frac{0}{n} \\
m \\
0 \\
0 \\
1\end{array}$ & $\begin{array}{l}\hat{b} \\
\dot{0} \\
x \\
n \\
\infty \\
0 \\
=\end{array}$ \\
\hline & & & & & $\mathrm{K}$ & $\begin{array}{c}\text { Over } \\
\mathrm{k}_{1}= \\
\mathrm{k}_{-1}\end{array}$ & $\begin{array}{l}\text { ate } \\
K \text { ad } \\
K \text { de }\end{array}$ & & ion & & & & \\
\hline
\end{tabular}

\section{CONCLUSION}

The carbons (PNSC \& TFR) are prepared from locally available cheap materials like, palm nut shells and fly ash. The properties of (PNSC \& TFR) are closed with ACC. The direct dye black $\mathrm{E}$ was obtained by commercially and using this dye a coloured solutions are prepared. The carbon have been used to adsorb the colouring matter from Black -E dye solution and to be adsorbed effectively and the adsorption of the dye on the carbon are almost 90-95\%.

The adsorption of the dye depends upon the initial concentration of the dye and upon $\mathrm{pH}$ condition and the carbon after use can be disposed without any effects are burnt easily.

The carbon can be reused at least five times without much reduction in the adsorption capacity. The Langmuir and freundlich constant are calculated for Black-E dye and also bed depth service time analysis has been done and depth to time dependency has been evaluated. 


\section{References}

[1] Khare S. K., Pandey K. K., Srivastava R. M., Singh V. N., J. Chem. Technol. Biotechnol. 38(2) (1987) 99

[2] Ahmed M. N., Ram R. N., J. Environ. Pollut. 37(2) (1992) 131.

[3] Manivannan, V., "Colour removal and dye house waste water", Ph.D. Thesis, Madras University, Madras (1985).

[4] Khanna P., Malhotra S. K., Indian J. Environ. Hlth. 19(3) (1977) 224-237.

[5] Karunakaran C., Manimekalai A., et al., Agricultural Application of Flyash, Proc. II Natl. Sem. On use of Flyash in Agriculture, Annamalai University, Annamalainagar, March 5\&6 (2001) 195-198.

[6] Kapadia M. J., Farasram R. P., Desai D. H., Bhatr M. M., Indian J. Environ. Protection, 20(7) (2000) 521-528.

[7] Allen W., Altherr E., Horning R. H., King J. C., Murphy J. M., Saltzaman M., Textile Chem., Colorists, 14 (1987) 6.

[8] Poots V. J. P., McKay G., Healy J. J., Water Res. 10 (1976) 1061-1067.

[9] Faust S. D., Aly O.M., "Chemistry of water treatment", Butter Worths, Bostan (1983).

[10] Hassler J. W., Chemical Publishing Co., Inc. New York 1951, 127.

[11] Ruby Jain, Manoj S. V., Gupta K. S., Indian J. Environ. Protection 19(1) (1999) 36-42.

[12] Methods of sampling and tests for activated carbon used for decolouring vegetable oils and sugar solutions, ISI-877 (1977).

[13] Vis J. H., Chemical Age of India 31 (1980) 5148.

[14] Nameto Deo, Manzoorali, Indian J. Environ. Protec. 13(7) (1993) 496-508.

[15] Gills C. H., Interpretation and use of sorption isotherms in sorption and transport process in soils. S.C.T. Monograph, No. 37, Society of Chemical Industry, London, 1970.

[16] Yonny D. M., Crowell A. D., "Physical Adsorption of Gases", Butter Worth Ltd., London (1962). 